Check for updates

Cite this: RSC Adv., 2020, 10, 6259

Received 6th September 2019 Accepted 21st December 2019

DOI: $10.1039 / c 9 r a 07147 d$

rsc.li/rsc-advances

\section{Stability of di-butyl-dichalcogenide-capped gold nanoparticles: experimental data and theoretical insights $\uparrow$}

\author{
Luiz Fernando Gorup, (D) *ae Bruno Perlatti, (D) a Aleksey Kuznetsov, (DD ${ }^{b}$ \\ Pedro Augusto de Paula Nascente, (D) ${ }^{c}$ Edison Perevalo Wendler, (D) ${ }^{a}$ Alcindo A. Dos \\ Santos, (D) Willyam Róger Padilha Barros, (D) Thiago Sequinel, (D) e \\ Isabela de Macedo Tomitao, ${ }^{e}$ Andressa Mayumi Kubo, (D) ${ }^{\text {a }}$ Elson Longo (D) ${ }^{a}$ \\ and Emerson Rodrigues Camargo (D) $^{a}$
}

\begin{abstract}
Metals capped with organochalcogenides have attracted considerable interest due to their practical applications, which include catalysis, sensing, and biosensing, due to their optical, magnetic, electrochemical, adhesive, lubrication, and antibacterial properties. There are numerous reports of metals capped with organothiol molecules; however, there are few studies on metals capped with organoselenium or organotellurium. Thus, there is a gap to be filled regarding the properties of organochalcogenide systems which can be improved by replacing sulfur with selenium or tellurium. In the last decade, there has been significant development in the synthesis of selenium and tellurium compounds; however, it is difficult to find commercial applications of these compounds because there are few studies showing the feasibility of their synthesis and their advantages compared to organothiol compounds. Stability against oxidation by molecular oxygen under ambient conditions is one of the properties which can be improved by choosing the correct organochalcogenide; this can confer important advantages for many more suitable applications. This paper reports the successful synthesis and characterization of gold nanoparticles functionalized with organochalcogenide molecules (dibutyldisulfide, dibutyl-diselenide and dibutyl-ditelluride) and evaluates the oxidation stability of the organochalcogenides. Spherical gold nanoparticles with diameters of $24 \mathrm{~nm}$ were capped with organochalcogenides and were investigated using X-ray photoelectron spectroscopy (XPS) to show the improved stability of organoselenium compared with organothiol and organotellurium. The results suggest that the organoselenium is a promising candidate to replace organothiol because of its enhanced stability towards oxidation by molecular oxygen under ambient conditions and its slow oxidation rate. The observed difference in the oxidation processes, as discussed, is also in agreement with theoretical calculations.
\end{abstract}

\section{Introduction}

Metal surfaces capped with organochalcogenides form hybrid materials composed of a combination of inorganic components (nanoparticles or films) and organochalcogenides. Their properties are of great interest in various fields, such as surfaceenhanced Raman spectroscopy, ${ }^{1}$ catalysis, ${ }^{2}$ sensors, ${ }^{3}$ biosensing and antibacterial agents, ${ }^{4}$ due to their optical and magnetic properties $^{5}$ and their electrochemical, ${ }^{6}$ adhesion, ${ }^{7}$ corrosion and lubrication characteristics. ${ }^{8}$

A popular procedure to obtain these hybrid materials is functionalization of the metal surface with organothiol molecules. ${ }^{9}$ Gold nanoparticles capped by organosulfur compounds on the surface have been well known for decades, and their structures, properties, and applications in diverse fields are still being investigated today. In marked contrast, the chemistry of 
metal nanoparticles capped with the heavier organochalcogens selenium and tellurium is still an exotic and underdeveloped field of nanotechnology. ${ }^{10}$ Development of synthetic selenium and tellurium compounds has been significant in the last decade; however, it is difficult to find commercial applications for these compounds due to the small number of studies showing the synthetic feasibility and, above all, the advantages of organoselenium and organotellurium compounds over organothiol compounds.

Many properties of these hybrid materials result from strong covalent interactions between the inorganic and organic phases, which is attributed to the strong affinity between the chalcogens (S, Se or Te) and gold, silver or platinum surfaces. ${ }^{\mathbf{1 1}}$ There are numerous reports describing the properties of hybrid materials formed with organothiol derivatives; ${ }^{12}$ however, fewer studies of organoselenium $^{\mathbf{1 3}}$ and organotellurium ${ }^{\mathbf{1 4}}$ have been reported. Recently, one of the authors of this work (A. A. Dos Santos and coworkers) demonstrated the unique characteristics and applications of nanostructured materials based on the synthesis of stable organo-telluro-polymer-capped gold nanostructures; they were found to be stable, dispersible in organic solvents and isolable. ${ }^{15}$ Despite this, there is still a gap to be filled in connection with the properties of previously studied organochalcogenide systems where sulfur is replaced with selenium or tellurium.

As shown by Mekhalif et al. ${ }^{16}$ copper surfaces covered by $n$ dodecaneselenol molecules are less susceptible to oxidation than $n$-dodecanethiol-covered surfaces, showing good blocking properties as well as corrosion inhibition efficiency. On the other hand, Nakamura et al. ${ }^{17}$ showed that organotellurium as an anchoring element on the $\mathrm{Au}(111)$ surface is more rapidly oxidized when exposed to air compared to an organosulfurcoated surface. In the present study, we perform the first characterizations of organochalcogenide molecules attached to the surface of gold nanoparticles in order to understand the peculiarities of organochalcogenides, more precisely the oxidation stability of the chalcogenide atoms.

In addition, we made the first attempt to compare the properties of three chalcogens, in the molecules dibutyl disulfide, dibutyl diselenide and dibutyl ditelluride, regarding their stability towards the oxidation process. We showed that the organoselenide is generally well-suited to form a compound with high stability to oxidation when compared to tellurium and sulfur. The fraction of oxidized molecules was evaluated quantitatively by X-ray photoelectron spectroscopy (XPS). Based on the results of this analysis, the oxidation stability of the capping molecule monolayers and Au NPs was analyzed. Theoretical calculations were performed as well, and their results corroborated the experimental data. We showed that organoselenium is more stable to the oxidation process than other organochalcogenides; thus, it is a promising candidate to replace organothiols in many applications due to the enhanced stability to oxidation by molecular oxygen under ambient conditions.

\section{Results and discussion}

Organochalcogenides have been targets of interest as intermediates and reagents in organic synthesis because of their synthetic applications and pharmacological properties. Several studies have shown that organic compounds of Se and Te exhibit pharmacological properties as potent therapeutic agents. Therefore, the combination of these molecules with nanoparticles can produce materials of great technological interest. ${ }^{18}$ Organoselenium and organotellurium compounds are very versatile, with numerous opportunities for research, development and applications such as antimicrobial activity, ${ }^{19}$ cancer treatment, ${ }^{20}$ glaucoma treatment, ${ }^{21}$ and catalysis. ${ }^{22} \mathrm{~S}$, Se and Te atoms have high affinity for noble metals such as silver, gold and platinum; also, due to their chemical similarity, both tellurium and selenium may eventually replace sulfur in a large number of molecules without increasing their toxicity or causing great environmental impact. ${ }^{23}$

Moreover, in some cases, this substitution can have a profound influence on the chemical properties of hybrid materials, especially when directly related to the covalent bonds between the heteroatoms and metal surfaces. ${ }^{24}$ There is a significant change in the electronic coupling between the heteroatom ligand and metal atoms, affecting the covalent bond energy between the metal and S, Se or Te; advantageously, the surfaces of metal nanoparticles can be modified with organoselenium $^{22,25}$ and organotellurium ${ }^{26}$ molecules which can be prepared by methods similar to those used in the synthesis of organosulfur. To prove the formation of the material, a combination of spectroscopic and microscopic techniques was employed; however, to understand the peculiarities of organochalcogenides, more precisely the oxidation stability of chalcogenide atom, X-ray photoelectron spectroscopy (XPS) studies were performed.

The gold nanoparticles were prepared by the citrate method (Fig. S1, ESI $\dagger$ ). Dibutyl dichalcogenides were added to the colloidal solution and mixed vigorously; stirring with a vortex favored the formation of bubbles and increased the surface contact between the surface of the nanoparticles and the dibutyl-dichalcogenides. Without stirring the solution, a change in the color of the solution from dark red to dark blue was observed; the intensity decreased with time until the aqueous fraction remained translucent. UV-vis analysis (Fig. 1d) showed the decreased red color intensity of the gold colloid in aqueous solution by absorption of the plasmon peak surface $(530 \mathrm{~nm})$, where the colorless state was reached at $30 \mathrm{~min}$. The decrease in the plasmon band at $530 \mathrm{~nm}$ is ascribed to a decrease in the number of spheroidal nanoparticles in aqueous solution during formation of the hybrid material because the nanoparticles are not soluble in aqueous solution after coating with organic molecules. The increase of the $800 \mathrm{~nm}$ band proves the formation of hybrid material agglomerates, which then can be re-dispersed in non-polar solvents.

The analysis by scanning electron microscopy (Fig. 1a and b) and transition electron microscopy (Fig. 1c) showed $24 \mathrm{~nm}$ gold nanoparticles covered by dibutyl ditelluride (Fig. 1f) (see the $\mathrm{ESI} \dagger$ for the other dibutyl dichalcogenides). The average particle size did not change after functionalization. The particle with its surface covered by molecules of dibutyl-dichalcogenides loses contact with the solution, and the stability of the nanoparticles in suspension is determined by the physical and chemical 

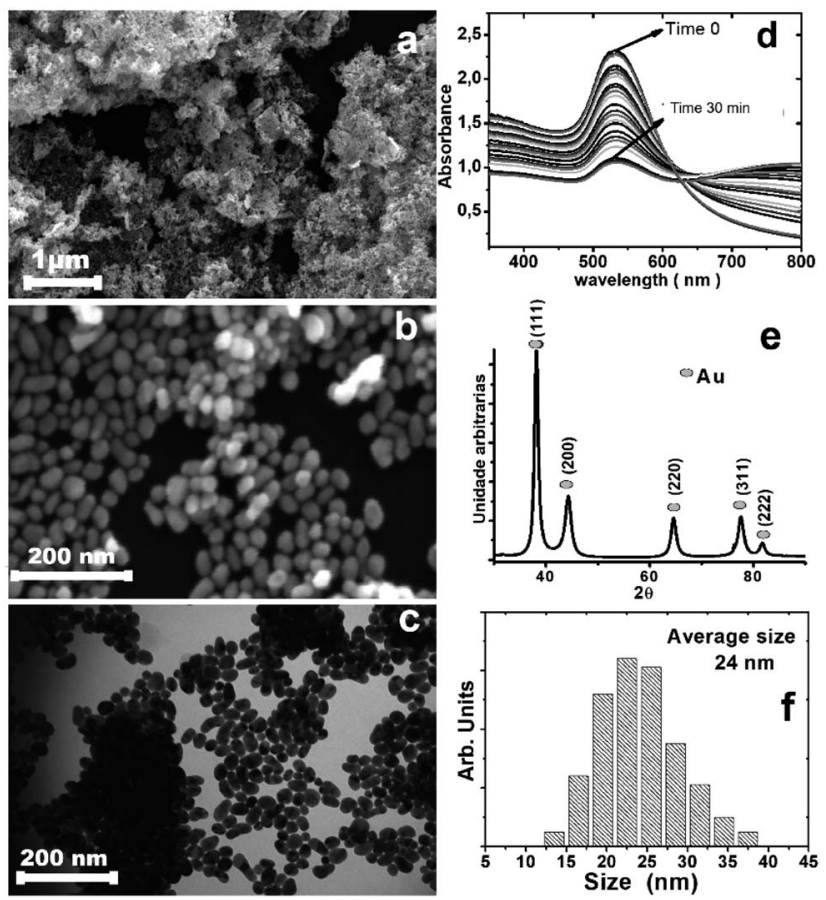

Fig. 1 ( $a$ and b) Scanning electron microscopy of gold nanoparticles passivated with dibutyl ditelluride on the silicon substrate; (c) transmission electron microscopy of gold nanoparticles passivated with dibutyl ditelluride; (d) UV-vis spectra of the colloidal nanoparticles as a function of time showing decreasing plasmon band intensity, suggesting a continuous decrease of the concentration of the particles in aqueous solution; (e) XRD pattern of the gold nanoparticles covered with dibutyl ditelluride; (f) the particle size distribution of the gold nanoparticles covered with dibutyl ditelluride, where the average size is $24 \mathrm{~nm}$.

characteristics of the molecules bonded on their surfaces. The functionalizing molecule has low solubility in aqueous medium; therefore, after the gold nanoparticles were functionalized, the system became more soluble in polar solvents because the interactions with the solvent molecules were exerted by the functionalizing molecules and not by the surfaces of the nanoparticles. ${ }^{27}$ The samples were deposited on a silicon substrate, dried and stored under ambient conditions of humidity, heat and oxygen. The X-ray, FT-IR, Raman, and XPS analyses were performed with these samples; this was important to evaluate the oxidation stability of the chalcogenide atoms.

Fig. 1e shows the XRD pattern for the obtained material, with peaks at $38.2^{\circ}, 44.4^{\circ}, 64.7^{\circ}, 77.6^{\circ}$, and $81.7^{\circ}$ that can be indexed to the (111), (200), (220), (311), and (222) reflections of the facecentered cubic (fcc) structure of metallic Au, respectively (PDF card 04-0784); the particle sizes from the Scherrer formula indicate monocrystalline particles. The calculated cell parameter of $4.115 \AA$ was very close to the value of $4.08 \AA$ found on the PDF card. ${ }^{28}$

The interactions (i.e., charge redistribution) between the anchoring elements and Au core were investigated by analyzing the Au $4 \mathrm{f}$ XPS spectra; these were fitted with two doublets, with $\mathrm{Au} 4 \mathrm{f}_{7 / 2}$ components at 84.2 and $85.8 \mathrm{eV}$ (see Fig. S9†). The lower energy component corresponds to metallic gold atoms located just below the first layer of atoms on the particle surface, while the higher energy component corresponds to gold atoms on the particle surface which are covalently bound to the carboxyl groups of citrate molecules $\left(-\mathrm{CO}_{2}-\right)$ or heteroatom molecules of the organochalcogenides $\mathrm{AuX}(\mathrm{X}=\mathrm{S}$, Se and $\mathrm{Te})$.

The $\mathrm{C}$ 1s peaks in Fig. $2 \mathrm{~b}-\mathrm{d}$ were fitted with two components: one at $284.8 \mathrm{eV}$, corresponding to the $\mathrm{C}-\mathrm{C}$ and/or C-H chains of aliphatic molecules of dibutyl-dichalcogenide adherent to surface of the nanoparticles, and a less intense component at $286.1 \mathrm{eV}$, corresponding to carbon covalently bound to the carboxyl group of citrate molecule $\left(-\mathrm{CO}_{2}-\right)$ or an atom of the chalcogenides $\mathrm{CX}(\mathrm{X}=\mathrm{S}$, Se and Te). A gold colloid sample stabilized only by citrate molecules was analyzed (Fig. 2a). The C

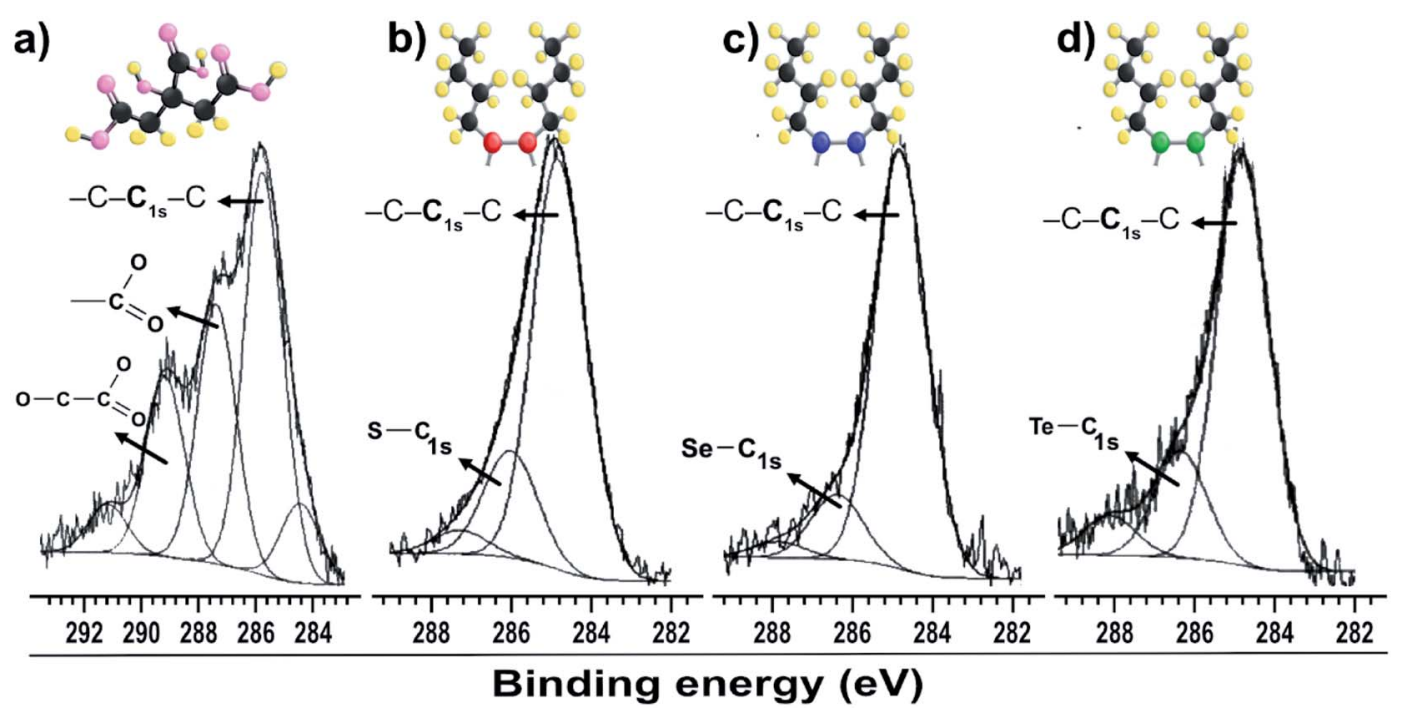

Fig. 2 XPS spectra of gold particles with surfaces passivated by (a) citrate C 1s; (b) dibutyl-thiol C 1s; (c) dibutyl-diselenide C 1s; (d) dibutylditelluride $C 1 \mathrm{~s}$. 


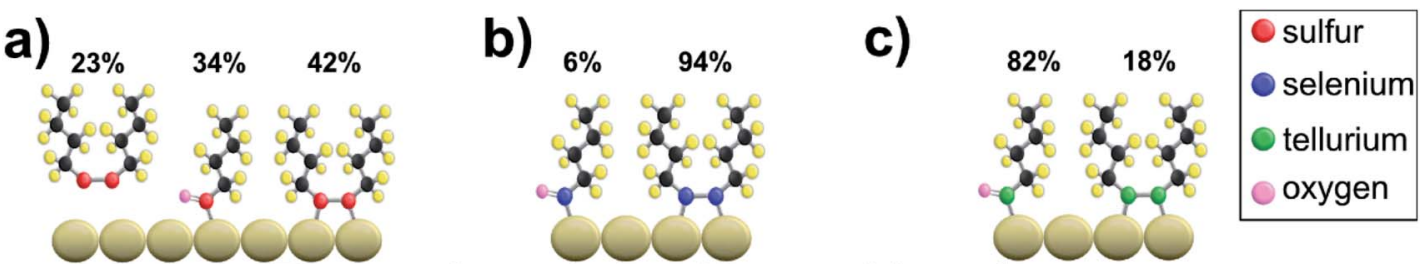

First layer of atoms in the gold nanoparticles surface

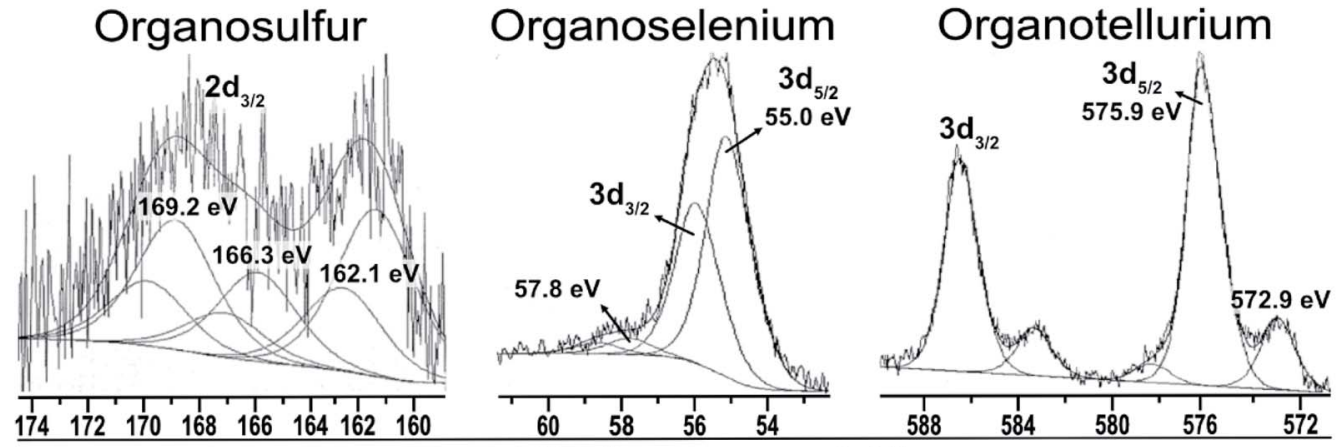

Binding energy (eV)

Fig. 3 XPS spectra of gold particles passivated with dibutyl-dichalcogenides: (a) dibutyl-thiol S 2p; (b) dibutyl-diselenide Se 3d; (c) dibutylditelluride Te $3 d$

1s peak was decomposed into three components, all corresponding to the adsorption of citrate. The component at lower energy is associated with hydrocarbon species $(\mathrm{C}-\mathrm{H} / \mathrm{C}-\mathrm{C}$; B. E. $=284.5$ to $285.7 \mathrm{eV}$ ), the component at intermediate energy is associated with carboxyl groups (C 1s with B. E. $=287.4 \mathrm{eV}$ ), and the component at higher energy is associated with carboxyl groups (C 1s with B. E. $=289.2 \mathrm{eV}$ ), which have the most electropositive carbons due to the proximity of the hydroxyl group. ${ }^{29}$ The XPS measurement results showed that the di-butyldichalcogenide-capped gold nanoparticles did not show a significant presence of citrate due to the absence of components reacting with the carboxyl groups. This indicates that the citrate molecules were replaced by di-butyl dichalcogenides on the surface of the gold nanoparticles.
Fig. 3a shows the dibutyl-disulfide S 2p spectrum, which was fitted by three doublets with $2 \mathrm{p}_{3 / 2}$ components at 162.1, 166.3 and $169.2 \mathrm{eV}$. These indicate the existence of three organothiol species. The $\mathrm{S} 2 \mathrm{p}_{3 / 2}$ component at approximately $162.1 \mathrm{eV}$ has a higher intensity and is associated with zero oxidation state sulfur, in other words, the dibutyl-disulfide $\left(\mathrm{But}_{2} \mathrm{~S}_{2}\right)$ species. The XPS data indicate that $43 \%$ of the total sulfur atoms bound to the gold nanoparticle surface are dibutyl-disulfide species $\left(\right.$ But $_{2} \mathrm{~S}_{2}$ ) (Fig. 4b). ${ }^{30}$ The S 2 $\mathrm{p}_{3 / 2}$ component with an intermediate energy of $166.3 \mathrm{eV}$ can be associated with a thiol unit; in other words, the component with intermediate energy is associated with a thiol molecule not bound to the nanoparticle surface. ${ }^{31}$ The S $2 \mathrm{p}_{3 / 2}$ component with a higher energy of $169.2 \mathrm{eV}$ can be associated with oxidized species of sulfur (sulfone $\mathrm{S}=0$ ) $;^{32}$ this

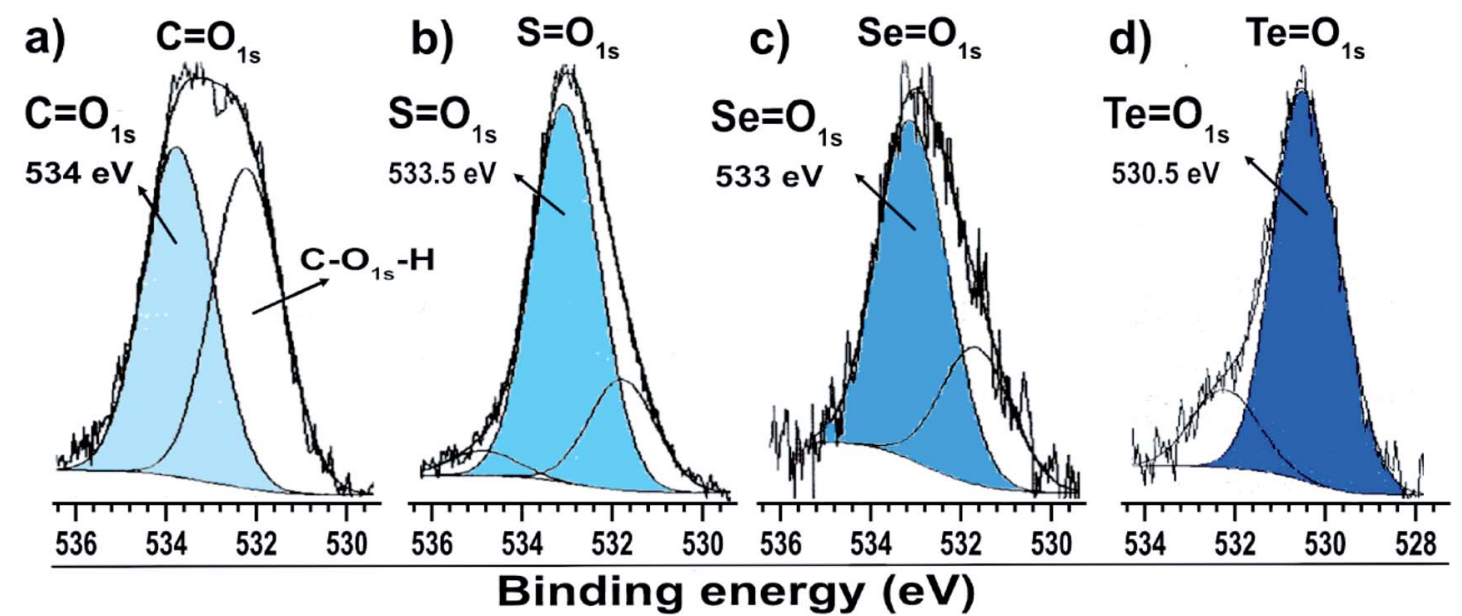

Fig. 4 O 1s XPS spectra of gold particles with surfaces passivated by (a) citrate, (b) dibutyl-thiol, (c) dibutyl-diselenol, and (d) dibutyl-ditelluride. 
is corroborated by the presence of the $\mathrm{O} 1 \mathrm{~s}$ peak at $533.5 \mathrm{eV}$ (Fig. 4b), indicating the formation of $\mathrm{S}=\mathrm{O}$ species. The peak areas correspond to the amount of chemical species, and the XPS data indicate that about $34 \%$ of the molecules of dibutyldisulfide underwent oxidation and that $23 \%$ of the molecules are not bound to the surface; in this case, one can presume that the sample was not adequately purified and an excess of dibutyldisulfide molecules was present. The percentage of molecules that underwent oxidation on the surface of the particles is $45 \%$. This oxidation is known and reported in the literature and contributes to greater reactivity of sulfur for oxidation. ${ }^{33}$

Fig. 3b shows the dibutyl-diselenide Se 3d spectrum fitted with two doublets, suggesting the existence of two species of selenium. The two doublets with more intense peaks with components at $55.0 \mathrm{eV}\left(3 \mathrm{~d}_{5 / 2}\right)$ and $55.9 \mathrm{eV}\left(3 \mathrm{~d}_{3 / 2}\right)$ are associated with selenium, referring to the same chemical state with zero oxidation state. The other, much less intense doublet has components at approximately $57.8 \mathrm{eV}\left(3 \mathrm{~d}_{5 / 2}\right)$ and $58.8 \mathrm{eV}\left(3 \mathrm{~d}_{3 / 2}\right)$, which are associated with the selenium +2 oxidation state. To identify the proportion of selenium in the two oxidation states, we used the $3 d_{5 / 2}$ peaks. In the present case, there are two such peaks: one very intense peak at $55.0 \mathrm{eV}$ and another less intense peak at approximately $57.8 \mathrm{eV}$.

The main $3 \mathrm{~d}_{5 / 2}$ peak with a binding energy of $55.0 \mathrm{eV}$ has a peak area of $94 \%$ and is associated with the same proportion of selenium with zero oxidation state, that is to say, the dibutyldiselenide species $\left(\mathrm{But}_{2} \mathrm{Se}_{2}\right.$ ) (Fig. $3 \mathrm{~b}$ ). The $3 \mathrm{~d}_{5 / 2}$ peak with a binding energy of $57.8 \mathrm{eV}$ has a peak area of $6 \%$ and is associated with the same proportion of selenium with the +2 oxidation state, or the oxidized species dibutyl-diselenide $\left(\mathrm{But}_{2} \mathrm{Se}_{2}=\mathrm{O}\right)$.

The low intensity doublet with a $3 \mathrm{~d}_{5 / 2}$ component at approximately $57.8 \mathrm{eV}$ can be associated with oxidized species of selenium; this was confirmed by the presence of the $\mathrm{O} 1 \mathrm{~s}$ peak at $533.1 \mathrm{eV}$ (Fig. 4c), which indicates the formation of $\mathrm{Se}=$ $\mathrm{O}$ species. However, it can also be attributed to the $\mathrm{Au} 5 \mathrm{p}_{3 / 2}$ peak, which has a binding energy approximately equal to $59 \mathrm{eV}$. The XPS data for the nanoparticles functionalized with organoselenol show that they have greater stability to oxidation compared to the organotellurol and organothiol nanoparticles because only $6 \%$ of the selenium atoms underwent oxidation.

Fig. 3c shows the Te 3d dibutyl-ditelluride spectrum; it was fitted with two doublets with $3 \mathrm{~d}_{5 / 2}$ components at 572.9 and $575.9 \mathrm{eV}$, which indicate the existence of two species of tellurium. The less intense component at $572.9 \mathrm{eV}$ is associated with tellurium in the zero-oxidation state, namely the dibutylditelluride $\left(\mathrm{But}_{2} \mathrm{Te}_{2}\right)$ species. The most intense component at $575.9 \mathrm{eV}$ is associated with oxidized species of tellurium. The difference of $3.0 \mathrm{eV}$ between the peaks indicates the presence of $\mathrm{Te}(\mathrm{IV})$, which is confirmed by the presence of the $\mathrm{O} 1 \mathrm{~s}$ peak at $530.3 \mathrm{eV}$ (Fig. 4d); this indicates the formation of $\mathrm{Te}=\mathrm{O}$ species. The obtained results of the latter observation are in agreement with the literature, e.g., Nakamura et al. ${ }^{34}$ showed that the XPS spectrum of dibutyl telluride deposited on $\mathrm{Au}(111)$ film exhibits peaks of Te $3 \mathrm{~d}_{5 / 2}$ at 572.1 and $573.7 \mathrm{eV}$.

There are reports that indicate that the oxidized species is dibutyl-ditelluroxide $($ ButTe $=0) .{ }^{35}$ This species is also connected to the surface of gold nanoparticles by binding through tellurium. The area of this peak represents the percentage of the chemical species, and the XPS data indicate that about $82 \%$ of the molecules of dibutyl-ditelluride underwent oxidation. This oxidation is known and reported in the literature, and it contributes to the greater reactivity of tellurium in oxidation among dibutyl-dichalcogenide molecules. ${ }^{36} \mathrm{It}$ is not a good candidate for applications where organotellurol molecules must retain their original properties; however, Nakamura et $a l .{ }^{37}$ showed that the oxidized species of dioctyl ditelluride remarkably enhance the resistive properties of the OcTe-oxide monolayers, which can lead to effective insulating properties when compared with disulfide and diselenide films.

The XPS analysis suggests that the dibutyl-diselenide molecules bound to the gold nanoparticle surface are more stable towards oxidation processes by oxygen species in air under ambient conditions than the other dibutyl-dichalcogenide molecules (Table 1). Tohru Nakamura et al. ${ }^{17}$ suggested that organoselenol and organothiol ligands are more stable than organotellurol ligands, presumably due to the lower oxidation potential of tellurium and the weaker C-Te bond energy than those of the lighter chalcogens $(\mathrm{O}, \mathrm{S}, \mathrm{Se})$. He showed that tellurophene molecules were gradually oxidized on the surface by oxygen in the atmosphere, faster than their selenium and thiol analogs.

The three dibutyl-dichacogenide samples were dried after reaction and analyzed by XPS two times, one day and 13 months after sample preparation. The XPS data show that the percentage of oxidized molecules did not change significantly in this period (Table 1); this indicates that oxidation of the chalcogenide occurs during the passivation of the surfaces of the particles, possibly caused by the contact with water. This result suggests a slow oxidation rate for dibutyl-dichalcogenidecapped gold nanoparticles under ambient conditions. The results show that the stability sequence in the oxidation of organochalcogenides is as follows: dibutyl-diselenide, dibutyldisulfide, and dibutyl-ditelluride. After one year, no significant oxidation of organoselenium was observed; thus, it is a promising candidate to replace organothiol in many applications because of its enhanced stability to oxidation by molecular oxygen under ambient conditions. The observed difference in the oxidation processes of dibutyl-dichalcogenides, as discussed above, is also in agreement with theoretical calculations. $^{38}$

Table 1 Stability of dibutyl-dichalcogenide molecules in the oxidation process by oxygen species in air under ambient conditions; percentages of oxidized molecules one day and 13 months after reaction

Percentages of oxidized molecules ButX $=\mathrm{O}$ $(\mathrm{X}=\mathrm{S}$, Se or $\mathrm{Te})$

Organic chalcogenide

One day after reaction

13 months after

Dibutyl-disulfide Dibutyl-diselenide Dibutyl-ditelluride

$\begin{array}{ll}45 \% & 49 \% \\ 6 \% & 7 \% \\ 82 \% & 83 \%\end{array}$




\subsection{Computational data on the oxidation energies of the capped Au NPs}

As models for our theoretical studies, $\mathrm{Au}_{20}$ nanoparticles capped either with 1 or $2 \mathrm{X}_{2} \mathrm{C}_{8} \mathrm{H}_{18}(\mathrm{X}=\mathrm{S}$, Se, Te) ligands, $\mathrm{Au}_{20}\left(\mathrm{X}_{2} \mathrm{C}_{8} \mathrm{H}_{18}\right)$ and $\mathrm{Au}_{20}\left(\mathrm{X}_{2} \mathrm{C}_{8} \mathrm{H}_{18}\right)_{2}$, were used (for discussion of the various DFT and especially molecular dynamics studies of ligand-capped $\mathrm{Au}$ NPs with different sizes and for justification of the usage of the $\mathrm{Au}_{20}$ model, please refer to the ESI $\dagger$ ). To identify the global minima structures of the model compounds, we performed geometry optimizations without any symmetry constraints followed by frequency calculations on both singlet and triplet structures of $\mathrm{Au}_{20}\left(\mathrm{X}_{2} \mathrm{C}_{8} \mathrm{H}_{18}\right)$ and $\mathrm{Au}_{20}\left(\mathrm{X}_{2} \mathrm{C}_{8} \mathrm{H}_{18}\right)_{2}$ using the density functional theory approach. ${ }^{39}$ It was found that for the $\mathrm{Au}_{20}\left(\mathrm{X}_{2} \mathrm{C}_{8} \mathrm{H}_{18}\right)$ species, the singlet structures were lower in energy than the triplets by 8.1 (8.0 with ZPE correction) kcal $\mathrm{mol}^{-1}$ for $\mathrm{X}=\mathrm{S}$ and by 5.4 (4.8 with ZPE correction) $\mathrm{kcal} \mathrm{mol}^{-1}$ for $\mathrm{X}=\mathrm{Se}$. However, for $\mathrm{X}=\mathrm{Te}$, the triplet structure was calculated to be lower in energy than the singlet by 6.1 (6.0) $\mathrm{kcal} \mathrm{mol}^{-1}$ (see the ESI $\dagger$ ). Interestingly, for all the $\mathrm{Au}_{20}\left(\mathrm{X}_{2} \mathrm{C}_{8} \mathrm{H}_{18}\right)_{2}$ species, singlets were found to be the lowestlying structures (ESI $\dagger$ ).

In Table 2, the calculated energies of the oxidation reactions of the $\mathrm{Au}$ NPs capped with 2 capping ligands, the $\mathrm{Au}_{20}\left(\mathrm{X}_{2} \mathrm{C}_{8} \mathrm{H}_{18}\right)_{2}$ species, are provided. We were interested in studying the oxidation reactions of the Au NPs with higher degrees of surface coverage by the ligands; thus, we decided to focus on the model structures containing 2 ligands. The optimized lowest-lying triplet structures of the $\mathrm{Au}_{20}\left(\mathrm{X}_{2} \mathrm{O}_{2} \mathrm{C}_{8} \mathrm{H}_{18}\right)_{2}$ species are given in the ESI. $\dagger$

For the oxidation of just one of the two capping ligands, the exothermicity of the reaction increased monotonically from $\mathrm{S}$ to Te, by $4 \mathrm{kcal} \mathrm{mol}^{-1}$ from $\mathrm{S}$ to Se and by $5.1 \mathrm{kcal} \mathrm{mol}^{-1}$ from Se to Te. That is, the exothermicity of the reaction increases with increasing atomic number of $\mathrm{X}$, as would be expected. However, the situation of the energy differences becomes noticeably different when both capping ligands are oxidized: the exothermicity of the reaction is calculated to change by $32.05 \mathrm{kcal} \mathrm{mol}^{-1}$ from $\mathrm{S}$ to Se and by $17.83 \mathrm{kcal} \mathrm{mol}^{-1}$ from Se to Te. That is, the reaction exothermicity first increases with increasing atomic number of $\mathrm{X}$ and then decreases. If we compare the average ligand binding energies calculated for 1 and 2 capping ligands (Fig. S15 $\dagger$ ), we can see that with 1 capping ligand, the binding energies increase essentially monotonically from $\mathrm{S}$ to $\mathrm{Te}$; however, with 2 capping ligands, there is a peak of the ligand binding energies at Se followed by a noticeable drop to Te. A closer look at the optimized structures of the 2 oxidized capping ligands (Fig. S16-S18†) tells us that significant changes in the ligand structures would take place upon oxidation: ${ }^{40}$ breakage of $\mathrm{X}-\mathrm{X}$ bonds, formation of $\mathrm{X}-\mathrm{O}-\mathrm{X}$ and $\mathrm{X}-\mathrm{O}-\mathrm{Au}$ bridges, and partial removal of ligands from the NP surface with apparent formation of weak van der Waals interactions between the broken ligands and the NP surface or other parts of the ligands (note: a similar situation was observed with the relatively long-chain $\mathrm{SCH}_{2} \mathrm{CO}_{2} \mathrm{H}$ ligands in the 2014 study of capped $\mathrm{Cd}_{33} \mathrm{X}_{33}(\mathrm{X}=\mathrm{Se}, \mathrm{Te}) \mathrm{NPs}$ performed by Kuznetsov and Beratan $\left.{ }^{41}\right)$. Therefore, the process of the capped ligand oxidation is very complicated, and many different factors, both thermodynamical (relative stabilities and reaction energies) and kinetic, should be taken into account when considering it. We can see that introduction of a second ligand in the models changes the ligand binding energies (see Fig. S15 $\dagger$ ); thus, the capped NPs with 2 S-containing ligands are more stable towards dissociation to the bare NPs and free ligands than the capped NPs with 2 Te-containing ligands, and the NPs with 2 Se-containing ligands are the most stable of all the three species. However, these relative stabilities should not be confused with the stabilities towards oxidation. According to previous studies (see the ESI $\dagger$ ), coverage of Au NPs with Secontaining ligands increases their stability against degradation in solution $^{42}$ (ref. 32 in the ESI $\dagger$ ); however, upon coverage of the Au NPs with the Te-containing ligands, it is difficult to completely prevent the oxidation of tellurolate in the nanoparticles ${ }^{\mathbf{4 3}}$ (ref. 33 and 34 in the ESI $\dagger$ ). We suppose that increasing the ligand binding energies from the S-containing to Se-containing ligands opposes the increase of the exothermicity of the oxidation reaction from $\mathrm{S}$ to $\mathrm{Se}$, and, in contrast, the significant decrease of the ligand binding energies from Se to Te opposes the decrease in the exothermicity of the oxidation reaction from Se to Te. Also, we suppose that mutual interactions of the ligands closely located at the NP surface and various changes in the ligand structures upon oxidation may change the reactivity of the ligand towards $\mathrm{O}_{2}$. We believe that complete understanding of the oxidation of Au NPs capped with ligands containing three different chalcogens will require further detailed theoretical and experimental investigations. However, we believe that we have provided explanations for the current experimental findings.

\section{Experimental section}

\subsection{Synthesis of gold nanoparticles}

Gold nanoparticles were prepared by the reduction of gold(III) chloride trihydrate (99.9\%, Sigma-Aldrich, USA) solutions with sodium citrate (99\% Synth, Brazil) by the standard procedure,

Table 2 Calculated energies of the oxidation reactions of the $\mathrm{X}_{2} \mathrm{C}_{8} \mathrm{H}_{18}(\mathrm{X}=\mathrm{S}$, Se, Te)-capped Au NPs, calculated at the PBEPBE/Lanl2dz level of theory

$\Delta E\left(\mathrm{Au}_{20}\left(\mathrm{X}_{2} \mathrm{C}_{8} \mathrm{H}_{18}\right)_{2}+\mathrm{O}_{2} \Rightarrow \mathrm{Au}_{20}\left(\mathrm{X}_{2} \mathrm{C}_{8} \mathrm{H}_{18}\right)_{2} \mathrm{O}_{2}\right)$ $\mathrm{kcal} \mathrm{mol}^{-1} / \mathrm{eV}$
$\Delta E\left(\mathrm{Au}_{20}\left(\mathrm{X}_{2} \mathrm{C}_{8} \mathrm{H}_{18}\right)_{2}+2 \mathrm{O}_{2} \Rightarrow \mathrm{Au}_{20}\left(\mathrm{X}_{2} \mathrm{O}_{2} \mathrm{C}_{8} \mathrm{H}_{18}\right)_{2}\right)$ kcal $\mathrm{mol}^{-1} / \mathrm{eV}$

$\mathrm{S}$

Se

$\mathrm{Te}$
$-1.43 /-0.062$

$-33.48 /-1.45$

$-51.31 /-2.23$ 
following the citrate method. ${ }^{\mathbf{4 4}}$ Solutions were prepared with deionized water obtained from a commercial Millipore Elix 3 system. All the chemicals used in this work were of analytical grade and were used as received with no further purification. A volume of $100 \mathrm{~mL}$ of an aqueous solution of $\mathrm{HAuCl}_{4}(1.0 \mathrm{mmol}$ $\mathrm{L}^{-1}$ ) was heated and stirred gently with a magnetic Tefloncoated bar. When the temperature of the $\mathrm{HAuCl}_{4}$ solution reached $90{ }^{\circ} \mathrm{C}, 1.0 \mathrm{~mL}$ of a $0.3 \mathrm{~mol} \mathrm{~L}^{-1}$ solution of sodium citrate preheated to $90^{\circ} \mathrm{C}$ was added, and the $\mathrm{pH}$ of the mixture, measured at room temperature, was maintained at 3 to 4 . After 8 minutes of reaction, the reaction mixture was removed from the heat and cooled to room temperature (Fig. 5).

\subsection{Synthesis of dibutyl-dichalcogenides}

Chemicals. Tellurium (200 mesh, 99.85\%), selenium, sulfur, sodium borohydride (powder, 98\%), bromine, iodine, $n$-butyl lithium solution, and 1-bromobutane (BuBr, 99\%) were purchased from Aldrich. Sodium sulfite was purchased from EMScience. Tetrabutylammonium bromide (TBAB, 98\%) was obtained from Alfa Aesar, and hydrogen tetrachloroaurate hydrate ( $49 \mathrm{wt} \% \mathrm{Au}$ ) was obtained from Strem Chemicals. The organic solvents dimethyl formamide, hexane, toluene, methanol, dichloromethane, ethanol, and tetrahydrofuran were of analytical grade. They were all used as received. Milli-Q water (18.2 M $\Omega$ ) was used. All glassware was cleaned in sulfuric acid with Nochromix and rinsed with a large amount of water before use.

Di-butyl disulfide was prepared by addition of $n$-butyl lithium (1 eq.) to a THF suspension of elemental sulfur followed by water and iodine. A similar procedure was adopted to prepare dibutyl ditelluride, omitting the treatment of the reaction media with iodine and exposing the intermediate tellurol to an oxygen atmosphere for the oxidation step. Di-butyl diselenide was prepared by reacting elemental selenium in aqueous basic media with hydrazine hydrate followed by addition of butyl bromide and tetrabutylammonium bromide. The synthetic reaction is summarized in Fig. 6. A detailed experimental procedure is presented in the ESI. $\dagger$

\subsection{Synthesis of hybrid materials}

The hybrid materials were prepared by anchoring dibutyldichalcogenide molecules on the surface of gold nanoparticles (Fig. 3). The colloidal gold nanoparticles used were obtained after eight minutes of reaction. The organic molecules of dibutyl-dichalcogenides were provided, synthesized and purified by the Laboratory of Organocatalytic and Synthesis of Bioactive Substances (ESI $\dagger$ ).

Three samples of hybrid materials were prepared simultaneously in duplicate; the three species of dibutyldichalcogenides used to passivate the surfaces of the gold nanoparticles were dibutyl-disulfide, dibutyl-diselenide, and dibutyl-ditelluride. $45 \mathrm{~mL}$ of gold colloid were mixed in a falcon tube with $5 \mathrm{~mL}$ of the functionalizing agent (organochalcogenide) solution (with a concentration of $45 \mathrm{mmol} \mathrm{L}^{-1}$ in chloroform). The mixture was stirred vigorously with a vortex (IKA® Vortex VG 3.35) at the number 4 position of the rotating knob. After 15 minutes of vigorous stirring, the color of the colloid changed from dark red to a dark blue tint, which lost intensity with time until the aqueous fraction remained translucent. The vigorous stirring of the solutions with a vortex favored the formation of bubbles and increased the surface contact between the surface of the particles and the dibutyldichalcogenides.

The functionalized nanoparticles formed a film in the organic phase. The organic phase with functionalized particles was collected, isolated by centrifugation $(3000 \mathrm{rpm}$ for 10 minutes) and washed several times with chloroform to remove excess functionalizing agent (Fig. 7). All syntheses were repeated at least twice, and the results were always reproducible. In order to standardize the functionalization, a $5: 1$ ratio of the functionalizing agent to the initial concentration of ions in the colloid was chosen. This stoichiometric relationship is apparent because it does not represent the stoichiometric relationship between the active sites and the functionalizing agent. Considering that particles with diameters of $24 \mathrm{~nm}$ have approximately $7 \%$ of their atoms on the surface, which are the active anchoring sites for the organochalcogenides, the stoichiometry of the functionalizing agent and active sites is $71: 1$.

Three samples with the three different dibutyldichalcogenide molecules were also prepared where the functionalization was processed without agitation. For the functionalization of the nanoparticles with the organochalcogenides, $5 \mathrm{~mL}$ of gold colloid were added to a quartz cuvette; then, $50 \mu \mathrm{L}$ of functionalizing agent $\left(0.10 \mathrm{~mol} \mathrm{~L}^{-1}\right)$ of the dibutyl dichalcogenide were added. The UV-vis spectra of each resulting solution were collected every minute in the range of 0 to 99 minutes. After one hundred minutes, the gold particles were collected and sedimented, washed $(5 \times)$ with chloroform and analyzed by scanning electron microscopy.

\subsection{Characterization}

DRX. Gold nanoparticles were characterized in the $2 \theta$ range from 20 to $110^{\circ}$ by X-ray diffraction (XRD) using a Rigaku D/max $2500 \mathrm{PC}$ diffractometer with $\mathrm{Cu} \mathrm{K} \alpha$ radiation operating at $40 \mathrm{kV}$ and $40 \mathrm{~mA}$. To collect the patterns, the nanoparticles were deposited on a silicon substrate by dripping the aqueous colloidal dispersion onto the substrate at room temperature and waiting for the solvent to evaporate.

TEM-MEV. Scanning transmission electron microscopy (STEM) images were recorded at $20 \mathrm{kV}$ using a FEG Zeiss Supra 35-VP, and scanning electron microscopy (SEM) images were recorded with a Zeiss DSM 940A. The samples were prepared by placing two or three drops of the dilute NP dispersion in water on carbon-coated copper grids (200 mesh, PELCO ${ }^{\circledR}$ CenterMarked Grids). Histograms were constructed using the public domain Image image processing software.

IR. The IR spectra were obtained using a Bruker infrared spectrometer. For the free Oct2Te2, the liquid sample was dropped onto a $\mathrm{KBr}$ pellet and covered with another $\mathrm{KBr}$ pellet. For the Au NPs, a small amount of NPs in solid form was mixed with $\mathrm{KBr}$ powder as a solid support and ground to an even 

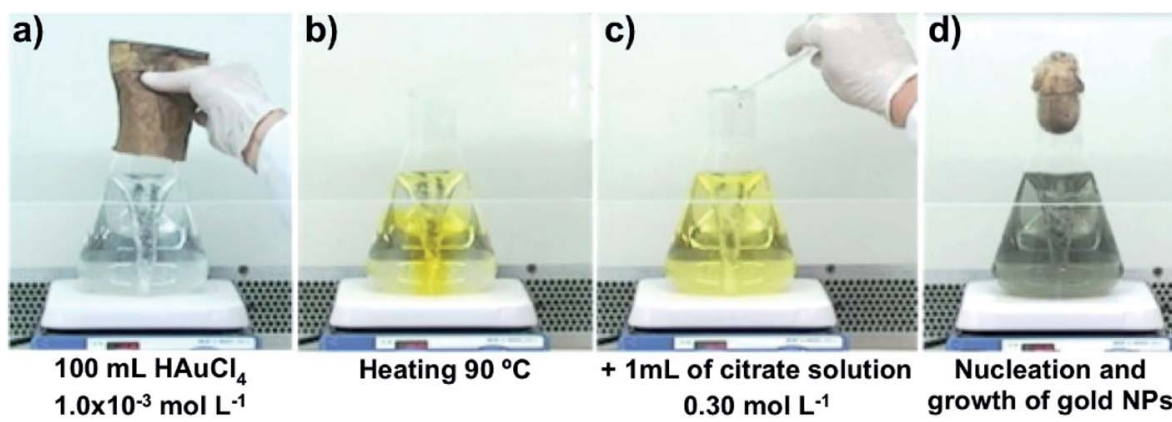

e)

Fig. 5 Synthesis of gold nanoparticles by the standard citrate method.

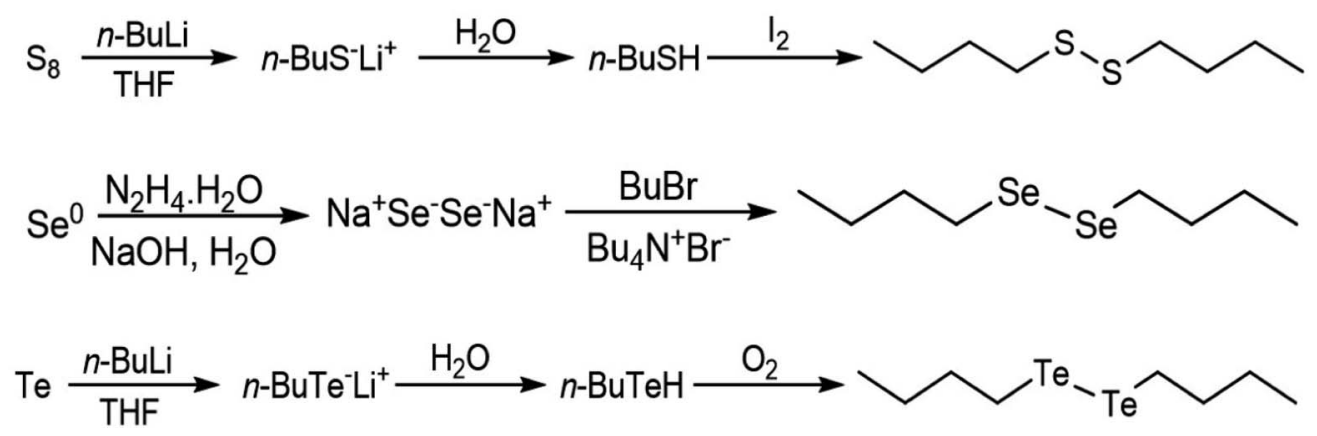

Fig. 6 Schemes of the syntheses of the dibutyl-dichalcogenides. ${ }^{45}$

mixture with a pestle. The mixture was pressed into a wafer for IR measurement. All measurements were performed in transmittance mode at $2 \mathrm{~cm}^{-1}$ resolution. The spectra were background subtracted with respect to $\mathrm{KBr}$ and subjected to baseline correction and smoothing.

UV-vis. For the UV-vis spectroscopy, colloidal gold was transferred into a $1.0 \mathrm{~cm}$ path length quartz cuvette, and the measurements were performed on a Shimadzu Multspec 1501
UV-vis spectrometer. A typical experiment scanned the wavelength range from 275 to $800 \mathrm{~nm}$. Background adjustments were made using water as a blank.

XPS. X-ray photoelectron spectroscopy (XPS) was used to assess the monolayer elemental composition and oxidation states of sulfur, selenium and tellurium atoms residing at the gold nanoparticle surface. XPS analyses were performed using a Kratos XSAM HS spectrometer with energy resolution greater

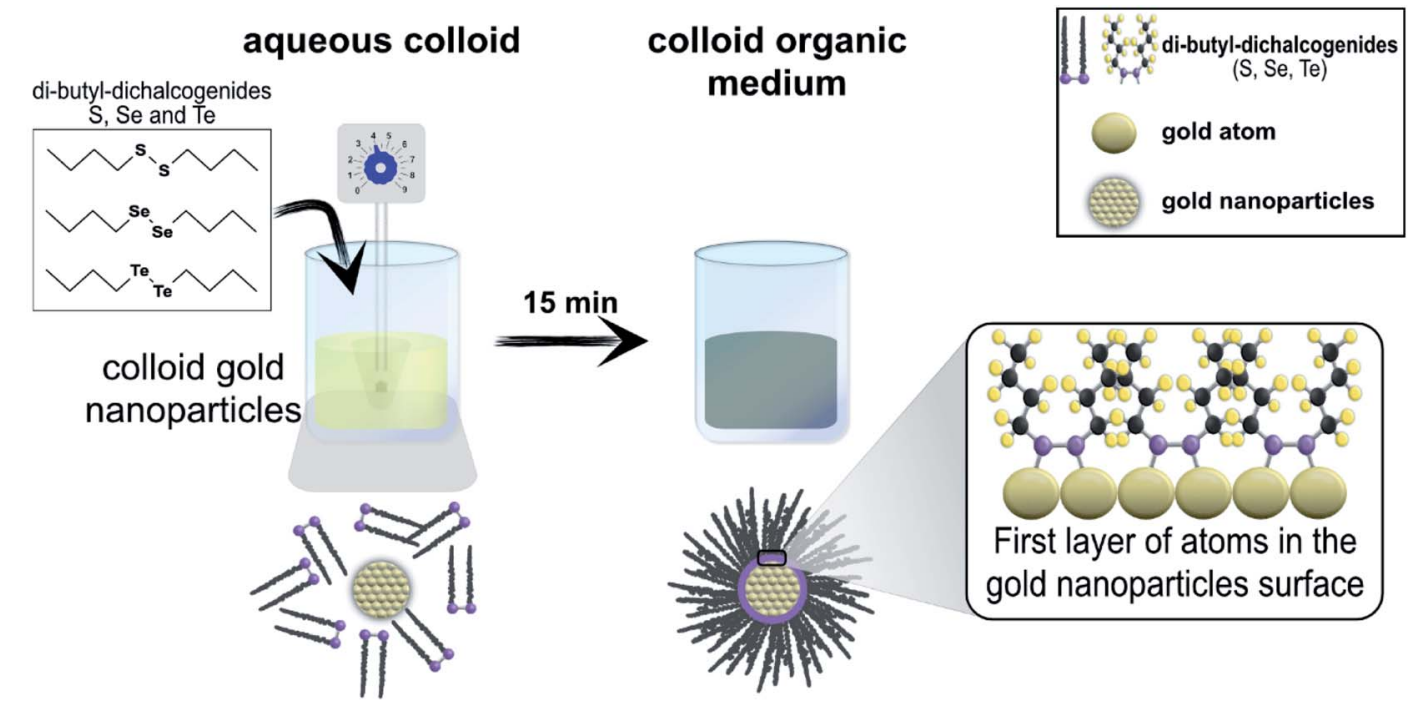

Fig. 7 Scheme of the synthesis of the hybrid materials (nanoparticles + dibutyl-dichalcogenide molecules). 
than $0.1 \mathrm{eV}$. The analyses were carried out in an ultrahigh vacuum atmosphere $\left(10^{-8}\right.$ Torr $)$ using magnesium $\mathrm{K} \alpha$ radiation as the excitation source, with an energy of $1253.6 \mathrm{eV}$ and $50 \mathrm{~W}$ power provided by $10 \mathrm{kV}$ voltage and $5 \mathrm{~mA}$ emission. A reference binding energy of $284.8 \mathrm{eV}$ was used for the $\mathrm{C}$ 1s peaks associated with $\mathrm{C}-\mathrm{C}$ and/or $\mathrm{C}-\mathrm{H} .{ }^{\mathbf{4 6}}$

Peak fittings were performed using Gaussian curves (for the $\mathrm{C}$ 1s and $\mathrm{O} 1 \mathrm{~s}$ peaks) and Gaussian/Lorentzian curves (for the Se $3 \mathrm{~d}$ and Te 3d doublets), background removal by the Shirley method, and the least-squares routine. ${ }^{47}$ The samples were deposited on Si (111) with an area of $1.5 \mathrm{~cm} \times 1.5 \mathrm{~cm}$ and mounted using conductive copper-backed double-sided adhesive carbon conductive tape (PELCO Tabs ${ }^{\mathrm{TM}}$, 16073). The sensitivity factors for quantitative analysis were referred to $S_{\mathrm{F} 1 \mathrm{~s}}$ $=1.0$. In the cases of alkanethiols, alkaneselenols and alkanetellurols, the $\mathrm{C} 1 \mathrm{~s}$ line mainly consists of carbon atoms from methylene groups that all have the same chemical environment (with the exception of the $\mathrm{C}$ atom bound to the head group); this line appears as a simple and well-defined structure in the spectra.

\section{Conclusions}

We report here the successful synthesis of hybrid materials with gold nanoparticles and a series of dibutyl-dichalcogenides (S, Se and Te). The average particle size of the formed Au NPs measured by transmission electron microscopy (TEM) was $24 \mathrm{~nm}$, and XPS was used to investigate the composition and structure of the capping monolayers and the formed Au NPs. We showed that organoselenium is more stable to the oxidation process than other organochalcogenides. After one year, no significant oxidation of organoselenium was observed; thus, it is a promising candidate to replace organothiol in many applications because of its enhanced stability to oxidation by molecular oxygen under ambient conditions. These characteristics were observed here for the first time. Theoretical calculations were performed, and their results supported the experimental results. Our future plans regarding these systems include studies of the kinetics of the autoxidation process and whether the structural quality of the films is fully preserved after autoxidation. In addition, it would be interesting to examine in more detail the initial stages of autoxidation of the organochalcogenides which are readily oxidized by oxygen species under ambient conditions, presumably by hydrogen oxide in the reaction solution rather than oxygen gas.

\section{Conflicts of interest}

There are no conflicts to declare.

\section{Acknowledgements}

This study was financed in part by the Coordenação de Aperfeiçoamento de Pessoal de Nível Superior - Brasil (CAPES) Finance Code 001; Conselho Nacional de Desenvolvimento Científico e Tecnológico (CNPq) 573636/2008-7, 306810/2015-8, 421648/2018-0, 435975/2018-8; and Grants 2008/57872-1, 20012/
07067-0, 2013/07297-0, 2013/07296-2, 2013/23572-0, 2016/ 01940-5, São Paulo Research Foundation (FAPESP). Special thanks to Rorivaldo Camargo and Madalena Turse for their contributions.

\section{References}

1 (a) S. W. Han and K. Kim, J. Colloid Interface Sci., 2001, 240, 492-497; (b) S. W. Han and K. Kim, J. Colloid Interface Sci., 2001, 240, 492-497; (c) M. Tahghighi, I. Mannelli, D. Janner and J. Ignés-Mullol, Appl. Surf. Sci., 2018, 447, 416-422; (d) F. C. Marques, G. P. Oliveira, R. A. R. Teixeira, R. M. S. Justo, T. B. V. Neves and G. F. S. Andrade, Vib. Spectrosc., 2018, 98, 139-144; (e) M. J. Ndolomingo and R. Meijboom, Appl. Surf. Sci., 2016, 390, 224-235.

2 (a) S. Ahammed, S. Bhadra, D. Kundu, B. Sreedhar and B. C. Ranu, Tetrahedron, 2012, 68, 10542-10549; (b) F. L. Coelho, L. C. Dresch, R. Stieler, L. F. Campo and P. H. Schneider, Catal. Commun., 2019, 121, 19-26; (c) H. B. Lu, C. T. Campbell and D. G. Castner, Langmuir, 2000, 16, 1711-1718; (d) S. Bhat, R. P. Narayanan, A. Baksi, P. Chakraborty, G. Paramasivam, R. R. J. Methikkalam, A. Nag, G. Natarajan and T. Pradeep, J. Phys. Chem. C, 2018, 122, 19455-19462.

3 A. K. K. Bhasin, J. Singh, H. Singh, P. Raj, N. Singh, N. Kaur and K. K. Bhasin, Polyhedron, 2017, 125, 238-245.

4 A. Kamal, M. Nazari V, M. Yaseen, M. A. Iqbal, M. B. K. Ahamed, A. S. A. Majid and H. N. Bhatti, Bioorg. Chem., 2019, 90, 103042.

5 (a) X. Chen, H. Wang, N.-S. Xu, H. Chen and S. Deng, Appl. Mater. Today, 2019, 15, 145-152; (b) M. Godoi, D. G. Liz, E. W. Ricardo, M. S. T. Rocha, J. B. Azeredo and A. L. Braga, Tetrahedron, 2014, 70, 3349-3354; (c) B. Mohan and K. H. Park, Appl. Catal., A, 2016, 519, 78-84; (d) M. Vanzan and S. Corni, J. Phys. Chem. A, 2018, 122, 68646872; (e) C. M. Aikens, Acc. Chem. Res., 2018, 51, 3065-3073. 6 (a) Z. Mekhalif, G. Fonder, F. Laffineur and J. Delhalle, J. Electroanal. Chem., 2008, 621, 245-253; (b) M. Navarro, Curr. Opin. Electrochem., 2017, 2, 43-52.

7 S. Chaudhary, A. Umar and S. K. Mehta, Prog. Mater. Sci., 2016, 83, 270-329.

8 (a) R. G. Nuzzo and D. L. Allara, J. Am. Chem. Soc., 1983, 105, 4481-4483; (b) R. G. Nuzzo and D. L. Allara, J. Am. Chem. Soc., 1983, 105, 4481-4483.

9 (a) J. Denayer, J. Delhalle and Z. Mekhalif, J. Electroanal. Chem., 2009, 637, 43-49; (b) P. Kumar, Z. Li and S. L. Wong, in Biomedical Applications of Functionalized Nanomaterials, ed. B. Sarmento and J. das Neves, Elsevier, 2018, pp. 289-314.

10 (a) M. B. Moretto, C. Funchal, G. Zeni, J. B. T. Rocha and R. Pessoa-Pureur, Toxicology, 2005, 210, 213-222; (b) M. B. Moretto, A. P. Thomazi, G. Godinho, T. M. Roessler, C. W. Nogueira, D. O. Souza, S. Wofchuk and J. B. T. Rocha, Toxicol. in Vitro, 2007, 21, 639-645; (c) C. I. Acker, R. Brandão, A. R. Rosário and C. W. Nogueira, Environ. Toxicol. Pharmacol., 2009, 28, 280-287. 
11 (a) A.-B. Witte, K. Anestål, E. Jerremalm, H. Ehrsson and E. S. J. Arnér, Free Radic. Biol. Med., 2005, 39, 696-703; (b) P. E. Laibinis, G. M. Whitesides, D. L. Allara, Y. T. Tao, A. N. Parikh and R. G. Nuzzo, J. Am. Chem. Soc., 1991, 113, 7152-7167; (c) Selenium and Tellurium Chemistry: From Small Molecules to Biomolecules and Materials, ed. J. D. Woollins and R. Laitinen, Springer, 2011.

12 (a) I. G. Dance, Polyhedron, 1986, 5, 1037-1104; (b) J. Denayer, J. Delhalle and Z. Mekhalif, Appl. Surf. Sci., 2009, 256, 1426-1430; (c) W. G. Salgueiro, B. S. Goldani, T. V. Peres, A. Miranda-Vizuete, M. Aschner, J. B. T. da Rocha, D. Alves and D. S. Ávila, Free Radic. Biol. Med., 2017, 110, 133-141; (d) J. Darkwa, E. Y. Osei-Twum and L. A. Litorja, Polyhedron, 1999, 18, 1115-1122; (e) C. W. Nogueira, V. C. Borges, G. Zeni and J. B. T. Rocha, Toxicology, 2003, 191, 169-178; (f) W. Hassan, M. Ibrahim, C. W. Nogueira, A. L. Braga, A. M. Deobald, I. u. MohammadZai and J. B. T. Rocha, Chem.-Biol. Interact., 2009, 180, 47-53.

13 (a) R. Caputo, S. Capone, M. D. Greca, L. Longobardo and G. Pinto, Tetrahedron Lett., 2007, 48, 1425-1427; (b) S. Babikanyisa and J. Darkwa, Inorg. Chim. Acta, 1997, 256, 15-20; (c) S. Chaudhary, A. Umar and S. K. Mehta, Prog. Mater. Sci., 2016, 83, 270-329; (d) A. Pop and A. Silvestru, Polyhedron, 2019, 160, 279-285.

14 (a) K. Mariappan, S. J. P. Varapragasam, M. R. Hansen, S. Rasalingam, M. Alaparthi and A. G. Sykes, J. Organomet. Chem., 2018, 866, 251-256; (b) W. G. Salgueiro, B. S. Goldani, T. V. Peres, A. Miranda-Vizuete, M. Aschner, J. B. T. da Rocha, D. Alves and D. S. Ávila, Free Radic. Biol. Med., 2017, 110, 133-141; (c) L. Heimfarth, F. da Silva Ferreira, P. Pierozan, M. R. Mingori, J. C. F. Moreira, J. B. T. da Rocha and R. Pessoa-Pureur, Toxicology, 2017, 379, 1-11; (d) L. Piovan, P. Milani, M. S. Silva, P. G. Moraes, M. Demasi and L. H. Andrade, Eur. J. Med. Chem., 2014, 73, 280-285.

15 (a) Fernández-Lodeiro, B. Rodríguez-González, H. M. Santos, E. Bertolo, J. L. Capelo, A. A. Dos Santos and C. Lodeiro, ACS Omega, 2016, 1, 1314-1325; (b) L. M. S. Takata, A. C. Gonçalves, R. A. Ando, A. A. Dos Santos and P. H. C. Camargo, J. Raman Spectrosc., 2012, 43, 712-717.

16 Z. Mekhalif, G. Fonder, D. Auguste, F. Laffineur and J. Delhalle, J. Electroanal. Chem., 2008, 618, 24-32.

17 (a) T. Nakamura, T. Miyamae, D. Yoshimura, N. Kobayashi, H. Nozoye and M. Matsumoto, Langmuir, 2005, 21, 50265033; (b) T. Nakamura, R. Kimura, F. Matsui, H. Kondoh, T. Ohta, H. Sakai, M. Abe and M. Matsumoto, Langmuir, 2000, 16, 4213-4216.

18 (a) M. Godoi, D. G. Liz, E. W. Ricardo, M. S. T. Rocha, J. B. Azeredo and A. L. Braga, Tetrahedron, 2014, 70, 33493354; (b) A. F. Keppler, R. A. Gariani, D. G. Lopes and J. V. Comasseto, Tetrahedron Lett., 2009, 50, 2181-2184; (c) W. Munbunjong, E. H. Lee, P. Ngernmaneerat, S. J. Kim, G. Singh, W. Chavasiri and D. O. Jang, Tetrahedron, 2009, 65, 2467-2471; (d) J. L. Princival, M. S. C. de Oliveira, A. A. Dos Santos and J. V. Comasseto, Tetrahedron: Asymmetry, 2009, 20, 2699-2703; (e) A. Singhal, V. K. Jain,
B. Varghese and E. R. T. Tiekink, Inorg. Chim. Acta, 1999, 285, 190-196; (f) N. Taniguchi, Tetrahedron, 2009, 65, 2782-2790; $(g)$ N. Taniguchi, Tetrahedron, 2016, 72, 58185823.

19 M. S. Gularte, J. M. Anghinoni, L. Abenante, G. T. Voss, R. L. de Oliveira, R. A. Vaucher, C. Luchese, E. A. Wilhelm, E. J. Lenardão and A. R. Fajardo, Carbohydr. Polym., 2019, 219, 240-250.

20 (a) S. Shaaban, A. M. Ashmawy, A. Negm and L. A. Wessjohann, Eur. J. Med. Chem., 2019, 179, 515-526; (b) S. Shaaban, A. M. Ashmawy, A. Negm and L. A. Wessjohann, Eur. J. Med. Chem., 2019, 179, 515-526.

21 D. Tanini, A. Capperucci, M. Scopelliti, A. Milaneschi, A. Angeli and C. T. Supuran, Bioorg. Chem., 2019, 89, 102984.

22 X. Deng, H. Cao, C. Chen, H. Zhou and L. Yu, Sci. Bull., 2019, 64, 1280-1284.

23 A. J. Sahani, R. V. Jayaram and A. S. Burange, Mol. Catal., 2018, 450, 14-18.

24 (a) J. S. Dhau, R. Dhir, A. Singh, P. Brandão and V. Félix, Inorg. Chim. Acta, 2013, 404, 160-166; (b) A. F. Keppler, R. A. Gariani, D. G. Lopes and J. V. Comasseto, Tetrahedron Lett., 2009, 50, 2181-2184; (c) A. Singhal, V. K. Jain, B. Varghese and E. R. T. Tiekink, Inorg. Chim. Acta, 1999, 285, 190-196; (d) M. S. Thomas, J. Darkwa, E. Y. Osei-Twum and L. A. Litorja, Polyhedron, 1999, 18, 2803-2810.

25 (a) S. Shaaban, A. M. Ashmawy, A. Negm and L. A. Wessjohann, Eur. J. Med. Chem., 2019, 179, 515-526; (b) A. Kamal, M. Nazari V, M. Yaseen, M. A. Iqbal, M. B. K. Ahamed, A. S. A. Majid and H. N. Bhatti, Bioorg. Chem., 2019, 90, 103042; (c) Y. Kim and D. Y. Kim, Tetrahedron Lett., 2019, 60, 1538-1542; (d) A. Pop and A. Silvestru, Polyhedron, 2019, 160, 279-285; (e) V. A. Potapov, R. S. Ishigeev, S. V. Amosova and T. N. Borodina, Tetrahedron Lett., 2019, 60, 475-479.

26 (a) W. Hou, Y. Zhou, J. Rui, R. Bai, A. K. K. Bhasin and B. H. Ruan, Bioorg. Med. Chem. Lett., 2019, 29, 1673-1676; (b) B. Kandasamy, B. S. Bassil, A. Haider, J. Beckmann, B. Chen, N. S. Dalal and U. Kortz, J. Organomet. Chem., 2015, 796, 33-38; (c) N. Petragnani and H. A. Stefani, in Tellurium in Organic Synthesis, ed. N. Petragnani and H. A. Stefani, Academic Press, London, 2nd edn, 2007, pp. 331335; (d) P. Singh, A. K. Gupta, S. Sharma, H. B. Singh and R. J. Butcher, Inorg. Chim. Acta, 2018, 483, 218-228; (e) P. C. Srivastava, V. Singh, S. Dwivedi, T. Pujan, A. K. Bhuj, R. J. Butcher, M. Bala Murali Krishna and D. Narayana Rao, Polyhedron, 2012, 42, 36-42; (f) S. Yamago, K. Iida and J.-i. Yoshida, Tetrahedron Lett., 2001, 42, 5061-5064.

27 (a) R. A. Sperling and W. J. Parak, Philos. Trans. R. Soc., A, 2010, 368, 1333-1383; (b) J. Tomasi and M. Persico, Chem. Rev., 1994, 94, 2027-2094.

28 (a) J. Heo, D.-S. Kim, Z. H. Kim, Y. W. Lee, D. Kim, M. Kim, K. Kwon, H. J. Park, W. S. Yun and S. W. Han, Chem. Commun., 2008, 6120-6122; (b) L. Cheng, X. Li and J. Dong, J. Mater. Chem. C, 2015, 3, 6334-6340.

29 (a) A. Calborean, F. Martin, D. Marconi, R. Turcu, I. E. Kacso, L. Buimaga-Iarinca, F. Graur and I. Turcu, Mater. Sci. Eng. C, 
2015, 57, 171-180; (b) N. Tawil, E. Sacher, E. Boulais, R. Mandeville and M. Meunier, J. Phys. Chem. C, 2013, 117, 20656-20665.

30 H. B. Lu, C. T. Campbell and D. G. Castner, Langmuir, 2000, 16, 1711-1718.

31 S. Zhang, G. Leem, L.-o. Srisombat and T. R. Lee, J. Am. Chem. Soc., 2008, 130, 113-120.

32 S. R. Johnson, S. D. Evans, S. W. Mahon and A. Ulman, Langmuir, 1997, 13, 51-57.

33 (a) W. de Poel, A. Gasseling, P. Mulder, A. P. G. Steeghs, J. A. A. W. Elemans, W. J. P. van Enckevort, A. E. Rowan and E. Vlieg, Surf. Sci., 2017, 662, 59-66; (b) M. H. Nielsen and J. R. I. Lee, in Methods in Enzymology, ed. J. J. De Yoreo, Academic Press, 2013, vol. 532, pp. 209-224; (c) S. Rajalingam, S. Devillers, J. Dehalle and Z. Mekhalif, Thin Solid Films, 2012, 522, 247-253; (d) J. Denayer, J. Delhalle and Z. Mekhalif, Thin Solid Films, 2012, 520, 2017-2021; (e) M. Kind and C. Wöll, Prog. Surf. Sci., 2009, 84, 230-278; (f) M.-Y. Tsai and J.-C. Lin, J. Colloid Interface Sci., 2001, 238, 259-266; (g) W. R. Everett and I. Fritsch-Faules, Anal. Chim. Acta, 1995, 307, 253-268.

34 T. Nakamura, T. Miyamae, I. Nakai, H. Kondoh, T. Kawamoto, N. Kobayashi, S. Yasuda, D. Yoshimura, T. Ohta, H. Nozoye and M. Matsumoto, Langmuir, 2005, 21(8), 3344-3353.

35 (a) Y. Li, L. C. Silverton, R. Haasch and Y. Y. Tong, Langmuir, 2008, 24, 7048-7053; (b) J. Penz, T. Gemelli, C. A. S. Carvalho, R. B. Guerra, L. Oliboni, M. Salvador, C. Dani, A. S. Araújo and C. Funchal, Food Chem. Toxicol., 2009, 47, 745-751.

36 (a) Y. Li, L. C. Silverton, R. Haasch and Y. Y. Tong, Langmuir, 2008, 24, 7048-7053; (b) R. H. Revanna, R. K. Panchangam, U. Bhanu and S. Doddavenkatanna, J. Braz. Chem. Soc., 2016, 27, 1157-1164; (c) C. R. Princival, M. V. L. R. Archilha, A. A. Dos Santos, M. P. Franco, A. A. C. Braga, A. F. Rodrigues-Oliveira, T. C. Correra, R. L. O. R. Cunha and J. V. Comasseto, ACS Omega, 2017, 2, 4431-4439; (d) H. Park, L. J. Edgar, M. A. Lumba, L. M. Willis and M. Nitz, Org. Biomol. Chem., 2015, 13, 7027-7033; (e) S. S. Zade and H. B. Singh, PATAI'S Chemistry of Functional Groups, 2012.

37 T. Nakamura, S. Yasuda, T. Miyamae, H. Nozoye, N. Kobayashi, H. Kondoh, I. Nakai, T. Ohta, D. Yoshimura and M. Matsumoto, J. Am. Chem. Soc., 2002, 124(43), 12642-12643.

38 (a) C. A. Hosier and C. J. Ackerson, J. Am. Chem. Soc., 2019, 141, 309-314; (b) S. Bhat, R. P. Narayanan, A. Baksi, P. Chakraborty, G. Paramasivam, R. R. J. Methikkalam, A. Nag, G. Natarajan and T. Pradeep, J. Phys. Chem. C, 2018, 122, 19455-19462; (c) M. Vanzan and S. Corni, J. Phys. Chem. A, 2018, 122, 6864-6872; (d) C. M. Aikens, Acc. Chem. Res., 2018, 51, 3065-3073.

39 (a) We optimized the geometries and calculated the frequencies of the $\mathrm{Au}_{20}\left(\mathrm{X}_{2} \mathrm{C}_{8} \mathrm{H}_{18}\right)$ and $\mathrm{Au}_{20}\left(\mathrm{X}_{2} \mathrm{C}_{8} \mathrm{H}_{18}\right)_{2}$ species, along with the geometries and frequencies of the $\mathrm{Au}_{2} \mathrm{O} \quad \mathrm{NP}$ and $\mathrm{X}_{2} \mathrm{C}_{8} \mathrm{H}_{18}$ and $\mathrm{O}_{2}$ molecules, by using analytical gradients with the LANL2DZ basis sets the relativistic effective core potentials for $\mathrm{Au}$ and a generalized gradient approximation (GGA) method known in the literature as PBE. All calculations were performed by using the Gaussian 09 program; (b) M. J. Frisch, G. W. Trucks, H. B. Schlegel, G. E. Scuseria, M. A. Robb, J. R. Cheeseman, G. Scalmani, V. Barone, B. Mennucci, G. A. Petersson, H. Nakatsuji, M. Caricato, X. Li, H. P. Hratchian, A. F. Izmaylov, J. Bloino, G. Zheng, J. L. Sonnenberg, M. Hada, M. Ehara, K. Toyota, R. Fukuda, J. Hasegawa, M. Ishida, T. Nakajima, Y. Honda, O. Kitao, H. Nakai, T. Vreven, J. A. Montgomery, Jr, J. E. Peralta, F. Ogliaro, M. Bearpark, J. J. Heyd, E. Brothers, K. N. Kudin, V. N. Staroverov, T. Keith, R. Kobayashi, J. Normand, K. Raghavachari, A. Rendell, J. C. Burant, S. S. Iyengar, J. Tomasi, M. Cossi, N. Rega, J. M. Millam, M. Klene, J. E. Knox, J. B. Cross, V. Bakken, C. Adamo, J. Jaramillo, R. Gomperts, R. E. Stratmann, O. Yazyev, A. J. Austin, R. Cammi, C. Pomelli, J. W. Ochterski, R. L. Martin, K. Morokuma, V. G. Zakrzewski, G. A. Voth, P. Salvador, J. J. Dannenberg, S. Dapprich, A. D. Daniels, O. Farkas, J. B. Foresman, J. V. Ortiz, J. Cioslowski, and D. J. Fox, Gaussian 09, Revision D.01, Gaussian, Inc., Wallingford CT, 2013.

40 Note: in the starting structures for the oxidized ligands the $\mathrm{O}$ atoms were always coordinated to the X atoms. Molecular structures were visualized using OpenGL version of Molden 5.0 visualization software. G. Schaftenaar and J. H. Noordik, J. Comput.-Aided Mol. Des., 2000, 14, 123-134. 41 A. E. Kuznetsov and D. N. Beratan, J. Phys. Chem. C, 2014, 118, 7094-7109.

42 Y. Song, S. Wang, J. Zhang, X. Kang, S. Chen, Li Peng, H. Sheng and M. Zhu, Crystal Structure of SelenolateProtected $\mathrm{Au}_{24}(\mathrm{SeR})_{20}$ Nanocluster, J. Am. Chem. Soc., 2014, 136, 2963-2965.

43 (a) W. Kurashige, S. Yamazoe, M. Yamaguchi, K. Nishido, K. Nobusada, T. Tsukuda and Y. Negishi, $\mathrm{Au}_{25}$ Clusters Containing Unoxidized Tellurolates in the Ligand Shell, $J$. Phys. Chem. Lett., 2014, 5, 2072-2076; (b) Y. Li, L. C. Silverton, R. Haasch and Y. Y. Tong, Alkanetelluroxide-Protected Gold Nanoparticles, Langmuir, 2008, 24, 7048-7053.

44 (a) A. Kubo, L. Gorup, L. Toffano, L. Amaral, E. RodriguesFilho, H. Mohan, R. Aroca and E. Camargo, Colloids Interfaces, 2017, 1, 4; (b) L. F. Gorup, E. Longo, E. R. Leite and E. R. Camargo, J. Colloid Interface Sci., 2011, 360, 355358; (c) J. A. S. Souza, D. B. Barbosa, J. G. do Amaral, D. R. Monteiro, L. F. Gorup, F. N. de Souza Neto, R. A. Fernandes, G. L. Fernandes, E. R. de Camargo, A. M. Agostinho and A. C. B. Delbem, Indian J. Microbiol., 2019, 59, 147-153; (d) A. M. Kubo, L. F. Gorup, L. S. Amaral, E. Rodrigues-Filho and E. R. d. Camargo, Mater. Res., 2018, 21, 4; (e) A. M. Kubo, L. F. Gorup, L. S. Amaral, E. R. Filho and E. R. Camargo, Bioconjugate Chem., 2016, 27, 2337-2345; (f) G. Fernandes, A. Delbem, J. do Amaral, L. Gorup, R. Fernandes, F. de Souza Neto, J. Souza, D. Monteiro, A. Hunt, E. Camargo and D. Barbosa, Antibiotics, 2018, 7, 52. 
45 (a) J. V. Comasseto, R. A. Gariani, J. L. Princival, A. A. Dos Santos and F. K. Zinn, J. Organomet. Chem., 2008, 693, 2929-2936; (b) R. A. Gariani, A. A. D. Santos and J. V. Comasseto, Synth. Commun., 2008, 38, 789-795; (c) B. A. Sousa, A. F. Keppler, R. A. Gariani, J. V. Comasseto and A. A. Dos Santos, Tetrahedron, 2012, 68, 10406-10413; (d) M. A. d. Araujo, C. Raminelli and J. V. Comasseto, J. Braz. Chem. Soc., 2004, 15, 358-365; (e) D. Crich and Y. Zou, J. Org. Chem, 2005, 70, 3309-3311.

46 D. Briggs, Surf. Interface Anal., 1981, 3, 98.

47 P. A. P. Nascente, J. Mol. Catal. A: Chem., 2005, 228, 145-150. 